\title{
Microsporum gypseum
}

National Cancer Institute

\section{Source}

National Cancer Institute. Microsporum gypseum. NCI Thesaurus. Code C127736.

A species of soil-associated keratinophilic fungi in the phylum Ascomycota with a worldwide distribution. This species is known for causing diseases on human skin, particularly associated with rural and ag ricultural workers. 